\title{
МАССОВЫЙ ЧЕЛОВЕК И КУЛЬТУРА ОБЩЕСТВА ПОТРЕБЛЕНИЯ
}

\author{
Босов Дмитрий Вячеславович \\ к.с.н., доцент кафедры социологии и философии \\ ФГБОУИ ВО «Московский государственный \\ гуманитарно-экономический университет»
}

\begin{abstract}
Аннотация: Цель статьи: рассмотреть феномен массового человека в рамках потребностей культуры общества потребления. Методы: сравнительнокомпаративистский, системный. Результаты: выявлены сущность, характеристики массового человека как важного объекта в пространстве субъект-субъектных отношений и интеракций общества потребления и его культуры. Выводы: Массовый человек продуцируется культурой общества потребления, легитимируя антитворчество, самоограничение в интересах ценностей общества потребления.

Ключевые слова: массовый человек; культура общества потребления; массовая культура; симуляционная реальность; симулякр; постмодернизм; наука; творчество.
\end{abstract}

\section{THE MASS MAN AND THE CULTURE OF THE CONSUMER SOCIETY}

\section{Bosov Dmitry Vyacheslavovich}

\begin{abstract}
The purpose of the article: to consider the phenomenon of a mass person within the framework of the needs of the culture of a consumer society. Methods: comparative-comparative, systematic. Results: the essence, characteristics of a mass person as an important object in the space of subject-subject relations and interactions of the consumer society and its culture are revealed. Conclusions: A mass person is produced by the culture of the consumer society, legitimizing anticreativity, self-restraint in the interests of the values of the consumer society.

Key words: mass man; consumer society culture; Mass culture; simulation reality; simulacrum; postmodernism; the science; creation.
\end{abstract}


Массовый человек, следуя различным классификациям специалистов, является редуцируемым типом личности, личности самоограничиваемой, нетворческого характера или даже антитворческого, тем самым не желающей саморазвиваться. Суть в том, что сама ориентация в русле саморазвития в состоянии подвергнуть трансформации типичный жизненный настрой гедонистического характера, изменить не только цели деятельности и образ жизни данного человека. Об этом воочию заявляет сама культура общества потребления, позиционирующая и продвигающая по сути массового человека как идеального потребителя. Осуществляя данное воздействие на сознание массового человека, массовая культура и мейнстрим-кинематограф посредствой образов аудиовизуальной культуры (кинофильмов, телесериалов, рекламных роликов, соцсетей и др.) латентно легитимизирует важное положение общества потребления: саморазвитие и выбор творческих ценностей как основного приоритета в конце концов должны привести приведет к девиации, стигматизации и аутсайдерству как данности, а развитие творческого потенциала таланта и гениальности в непотребительских сферах - к безумию как неизбежной расплате за отчаянную дегустацию нового «запретного плода» - всецелого погружения в научное знание, творческий поиск. Об этом вторит принцип ломброзианства, укорененный в современном массовом кинематографе. Искателям научных и творческих вершин - таланту и гению завидовать глупо, продвигает в своих «предпочтительных прочтениях» (С. Холл) культура общества потребления. Именно гении и таланты должны испытывать зависть по отношению к массовому человеку: его в большинстве своем соответствию норме, его твердому стоянию массового человека на ногах, безразличному спокойствию, утилитарному и прагматическому принципам руководства, гедонистической устремленности как реализации способности пережить пусть примитивное, но все же счастье, нежели витать, пребывать в мире открытий творчества и абстракций, которые несут исключительно страдания в духе непризнания и непонимания («знания преумножают скорбь», Экклезиаст), становиться объектом издевательств и насмешек - проявлений неформальных негативных санкций общества потребления и т.п. Культура общества потребления осуществляет эффективное, успешное блокирование всех способов реализации, либо раскрытия творческого потенциала личности [1, с.58; 7, с. $58 ; 11$, с.709; 12, с.208; 14, с.26].

Однако сам массовый человек ощущает пустоту внутри в зоне данного блокирования, испытывая перманентную неудовлетворенность и скуку, 
несмотря на внушаемое ему чувство самодовольства и превосходства - ведь это всего лишь внушение и не более. Фрейдистский биологизм повергает в прах прежнее «Сверх-Я», характерное для традиционных и раннекапиталистических обществ, еще не избавившихся от груза культурных ценностей, норм, правил, требований, табу и т.п. Вместо него незаметно возникает новое «Сверх-Я» в виде ценностей, норм и правил, но именно потребительского (консюмеристского) характера, которое, не подавляя бессознательные инстинкты и желания («Оно»), напротив, демонстрирует иную крайность: выжимает их из человека, беззастенчиво манипулируя ими как наилучшими мотивационными основами возможной покупательной способности. Технология торжествует над ослабленным от гедонизма рассудком, не доросшим до стадии разума. Рыночный идол торжествует над христианским Богом [2, с.290; 3, с.171; 6, с.121; 10, с.404; 13, с.311].

Г. Маркузе подтвердил внедрение и распространение ложных потребностей в массовом обществе, считая данный процесс частью производства массового человека позднеиндустриального общества «одномерного человека», который, вопреки фрейдизму, пытается выйти из состояния депривации и фрустрации, по сути дела, созданными особой социальной ситуацией в обществе отчуждения и искусственно спровоцированными индустрией культуры, обращается не к сублимации, как выплеску инстинктов в более высокую, творческую сферу, а к десублимации, т.е., согласно Г. Маркузе, к замещению опосредованного удовлетворения непосредственным. Следуя выводам М. Фуко и Ж. Бодрийяра, современная экранная аудиовизуальная культура есть проявление регрессивного особого вида синтезирования десублимации и сублимации, в котором десублимация блокирует переход человеческих примитивных инстинктов на более высокий уровень реализации (творчество и научный поиск, реализация в сфере искусства и др.), а сублимация позволяет замещать опосредованным удовлетворением потребности непосредственные, но таким идеальным воплощением симуляционной реальности и симулякров, которое, на фоне которого блекнет непосредственное, реальное. Ж. Бодрийяр и другие постмодернисты подчеркивали особую привлекательность screen physicality («экранной телесности»), вытесняющей телесность реальности (homo somaticos). Соотнося «экранную жизнь» как эталон со своей массовой человек испытывает дискомфорт, выражаемый все в тех же фрустрации и депривации $[4$, c. $132 ; 9$, с. $501 ; 12$, с. $98 ; 14$, c. 122$]$. 
Согласно А. Маслоу, потребности осуществляют поддержку индивида как активной целостности, наиважнейшей из них является потребность в самореализации, которая связана с проявлением индивидуальных способностей, склонностей, свойств. По Л. Климовой, она является одной из высших и связана с творческой деятельностью. Это ничто иное как раскрытие внутреннего творческого потенциала в каждом человеке и его реализация. Но современная сложная социокультурная ситуация в России препятствует ее осуществлению, переориентируя людей на примитивное выживание и заражая их страхом материальной несостоятельности в мире экранных эталонов успешных и материально обеспеченных молодых людей, и женщин $[5$, c. $150 ; 8 ; 12$, c. $108 ; 14$, c.117].

\section{Список литературы}

1. Бахарев В.В., Босов, Д.В. Массовая культура: определение границ в соотношении культур, основные структурные элементы и функции / В.В. Бахарев, Д.В. Босов // Этносоциум и межнациональная культура. 2010. № 8 (32). С. 53-84.

2. Беленкова Л.Ю. Инклюзивное высшее образование как системная инновация / Л.Ю. Беленкова, И.Л. Руденко // Проблемы современного педагогического образования. - 2017. - № 56 (10) - С. 288-298.

3. Беленкова Л.Ю. Интеграция и инклюзия: проблемы, поиски, решения/ Л.Ю. Беленкова // Российский научный журнал. - 2013. - № 3 (34). C. $166-173$.

4. Босов Д.В., Доля Р.Ю. Анализ научных подходов к рассмотрению потенциала кинотерапии в работе с детьми, имеющими психические отклонения. Часть 2. Комплексный социологический анализ теоретических основ оказания адресной помощи / Д.В. Босов, Р.Ю. Доля // Вестник Майкопского государственного технологического университета. Вып. 1/44. Майкоп: Издательство ФГБОУ ВО «МГТУ», 2020. - С. 130-139.

5. Босов Д.В., Доля Р.Ю. Анализ подходов, теорий и концепций кинотерапии в работе с детьми с психическими отклонениями. Часть $1 /$ Д.В. Босов, Р.Ю. Доля // Вестник Майкопского государственного технологического университета. Вып. 4/43. - Майкоп: Издательство ФГБОУ ВО «МГТУ», 2019. - С. 143-153.

6. Босов, Д.В. Современный студент как «массовый человек» / Д.В. Босов //Высшее образование в России. 2009. № 4. С. 120-122. 
7. Волкова, О.А., Босов, Д.В. Репрезентация образа женщиныпрограммиста в зарубежных и российских фильмах / О.А. Волкова, Д.В. Босов // Гендерное измерение цифровой экономики: от стратегии к действию (20182030). Материалы Всероссийской конференции с международным участием. Иваново, 2018. С.55-60.

8. Волкова, О.А., Босов, Д.В., Доля, Р.Ю. Социологический анализ функциональной неграмотности среди подростков как угрозы интеллектуальному потенциалу семьи / О.А. Волкова, Д.В. Босов, Р.Ю. Доля // Взаимодействие семьи с другими социальными институтами как возможность преодоления социокультурных угроз в России. Материалы Межрегиональной научно-практической конференции. Саранск, 2020. С.26.

9. Костина, А.В., Флиер, А.Я. Культура: между рабством конъюнктуры, рабством обычая и рабством статуса / А.В. Костина, А.Я. Флиер. М.: Согласие,2001. 677 c.

10. Ломброзо Ч. Гениальность и помешательство; Женщина преступница и проститутка; Любовь у помешанных / Ч. Ломброзо. - 2е изд. - Мн: Поппури, 2004. $576 \mathrm{c}$.

11. Мертон Р. К. Социальная теория и социальная структура / Роберт Мертон; [пер. с англ. Е. Н. Егоровой и др.]. М.: АСТ: Хранитель, 2006. 873 с.

12. Скал, Д. Дж. Книга ужаса: история хоррора в кино / Дэвид Дж. Скал. СПб: Амфора, 2009. - 318 с.

13. Фромм, Э. Бегство от свободы / Э. Фромм. Мн.: Харвест, 2003. 571 с.

14. Хренов, Н.А. Социальная психология искусства: Переходная эпоха / Н.А. Хренов. - М.: Альфа-М, 2005. - 623 с.

(С) Д.В. Босов, 2022 